Int. J. Electrochem. Sci., 15 (2020) $3646-3659$

\title{
Optimization of Machining Parameters and Electrochemical Corrosion Behavior of hardened Cr12MoV Mold Steel
}

\author{
Chen Guangjun ${ }^{1,2, *}$, Hou Shuai ${ }^{2}$, Han Songxi $^{2}$, Wang Chuanliang ${ }^{3}$ \\ ${ }^{1}$ School of Mechanical Engineering, Tianjin University of Technology and Education, Tianjin 300222, \\ China \\ ${ }^{2}$ School of Mechanical Engineering, Jiamusi University, Jiamusi 154007, China \\ ${ }^{3}$ School of Mechanical Engineering, Shenyang Jianzhu University, Shenyang 110168, China \\ *E-mail: guangjunchen08@ sina.com
}

doi: $10.20964 / 2020.05 .49$

Received: 11 December 2019 / Accepted: 20 February 2020 / Published: 10 April 2020

Corrosive environment can influence on hardened steel containing $\mathrm{Cr} 12 \mathrm{MoV}$ dies during molding which lead to greatly reduce the service life of the molds. Therefore, it is important to investigate the influence of milling parameters on the corrosion resistance of the metal die surface. In this study, single factor cutting tests and electrochemical methods were used to study the effect of processing parameters on the corrosion resistance of $\mathrm{Cr} 12 \mathrm{MoV}$ steel die used traditionally in injection molding of plastics. Polarization curve and impedance spectrum of the material was measured in mixed acid solutions under different processing parameters. ZSimpWin software was used to fit the impedance data and to analyze the corrosion resistance of the steel alloy die. The surface morphology after corrosion was observed under a scanning electron microscope (SEM), and elemental analysis was done to characterize the corrosion products. The corrosion resistance of the $\mathrm{Cr} 12 \mathrm{MoV}$ die steel had a great correlation with the skewness and kurtosis of the surface morphology parameters. Skewness values closer to zero resulted in smaller kurtosis values and increased corrosion resistance of the machined surface during injection molding. Among different conditions, the change of cutting depth had little effect on the corrosion resistance of the material surface. However, the change in tool radius had a significant impact on the corrosion resistance of the workpiece. The SEM results revealed that the corrosion products were found to significantly accumulate on the surface of the workpiece which was in accordance with the electrochemical results.

Keywords: Electrochemical Corrosion, Milling Surface, Polarization Curve, Electrochemical impedance spectroscopy, Milling Parameters, Corrosion Morphology

\section{$\underline{\text { FULL TEXT }}$}


(C) 2020 The Authors. Published by ESG (www.electrochemsci.org). This article is an open access article distributed under the terms and conditions of the Creative Commons Attribution license (http://creativecommons.org/licenses/by/4.0/). 